\title{
The structure of calcium metaphosphate glass obtained from $x$-ray and neutron diffraction and reverse Monte Carlo modelling
}

\author{
K M Wetherall, D M Pickup, R J Newport and G Mountjoy \\ School of Physical Sciences, University of Kent, Canterbury CT2 7NH, UK \\ E-mail: kmw22@kent.ac.uk
}

Received 8 October 2008, in final form 12 November 2008

Published 10 December 2008

Online at stacks.iop.org/JPhysCM/21/035109

\begin{abstract}
The short range structure of $(\mathrm{CaO})_{0.5}\left(\mathrm{P}_{2} \mathrm{O}_{5}\right)_{0.5}$ glass has been studied using $\mathrm{x}$-ray and neutron diffraction and modelled using the reverse Monte Carlo method. Using this combination of techniques has allowed six interatomic correlations to be distinguished and fitted to obtain a set of bond lengths and coordination numbers that describe the structure of the glass. The glass consists of metaphosphate chains of phosphate tetrahedra and each phosphate unit has two non-bridging oxygen atoms available for coordination with $\mathrm{Ca}$. The $\mathrm{Ca}-\mathrm{O}$ correlation was fitted with two peaks at 2.35 and $2.86 \AA$, representing a broad distribution of bond lengths. The total $\mathrm{Ca}-\mathrm{O}$ coordination is 6.9 and is consistent with distorted polyhedral units such as capped octahedra or capped trigonal prisms. It is found that most non-bridging oxygen atoms are bonded to two calcium atoms. All of these observations are consistent with Hoppe's model for phosphate glasses. Furthermore, the medium range order is revealed to consist of phosphate chains intertwined with apparently elongated clusters of $\mathrm{Ca}$ ions, and the $\mathrm{Ca}-\mathrm{O}$ and $\mathrm{Ca}-\mathrm{P}$ correlations contributed significantly to the first sharp diffraction peak in $\mathrm{X}$-ray diffraction.
\end{abstract}

(Some figures in this article are in colour only in the electronic version)

\section{Introduction}

Historically, phosphate glasses had limited applications due to their poor durability, but the discovery in recent decades of a number of durable phosphate glasses has motivated many further studies [1]. Phosphate glasses are versatile because their properties can be tailored by altering their composition. This adaptability has enabled them to be used in lasers and optical systems [2], sensors, solid-state batteries, hermetic seals [3, 4], and biomaterials [5, 6]. Current developments in biomaterials are aimed at making them degrade and play an active role in tissue regeneration. Phosphate glasses have been found to be suitable candidates as they completely dissolve in aqueous media at a rate that can be controlled by the chemistry of the glass [5]. It is also possible to include ions routinely found in the human body that would be released when the glass was dissolved and then used to help rebuild the hard or soft tissue.
In particular, calcium phosphates have been under study as biocompatible glasses, glass ceramics and fibres due to their chemical similarity to the hydroxyapatite found in bone [7-10]. It has been found that the properties of these glasses are more highly dependant on the local atomic environment of calcium than on the phosphate network [1]. It is therefore important to understand the local structure of the calcium in glasses from the calcium phosphate system.

The primary features of the phosphate network in phosphate glasses were explained in an influential model by Van Wazer [11]. This is based on the $\mathrm{PO}_{4}$ tetrahedra having two types of oxygen atoms, bridging oxygen $\left(\mathrm{O}_{\mathrm{b}}\right)$ and non-bridging oxygen $\left(\mathrm{O}_{\mathrm{nb}}\right)$. A fully polymerized phosphate network has three $\mathrm{O}_{b}$ atoms and one $\mathrm{O}_{n b}$ atom per phosphate tetrahedra. When a network-modifier cation, such as $\mathrm{Ca}$, is added to the network, the proportion of $\mathrm{O}_{\mathrm{nb}}$ increases at the expense of $\mathrm{O}_{b}$. Important refinements of this model have been added by Hoppe [12]. The network modifier coordinates 
with $\mathrm{O}_{\mathrm{nb}}$ atoms, and the coordination of the cation with multiple phosphate tetrahedra leads to an effect called a repolymerization. The system stabilizes when all the $\mathrm{O}_{\mathrm{nb}}$ atoms are coordinated with one network-modifier cation. When the concentration of modifier cations is increased further their coordination with $\mathrm{O}_{\mathrm{nb}}$ atoms increases leading to a drastic change in the glass properties around $20 \mathrm{~mol} \%$ divalent metal oxide. This model is extended to describe the structure of less polymerized networks such as metaphosphates.

The present study concerns the calcium phosphate glass with composition $(\mathrm{CaO})_{0.5}\left(\mathrm{P}_{2} \mathrm{O}_{5}\right)_{0.5}$. The $\mathrm{O} / \mathrm{P}$ ratio of this glass is 3 making it a metaphosphate. At the metaphosphate composition each phosphate tetrahedra has on average two $\mathrm{O}_{\mathrm{b}}$ atoms linking to other phosphate units and two $\mathrm{O}_{\mathrm{nb}}$ atoms available for calcium coordination. IR and Raman spectroscopy results for metaphosphate glasses show a dominance of $Q^{2}$ groups (where $Q^{n}$ refers to a $\mathrm{PO}_{4}$ tetrahedra with connectivity of $n$ ) [13]. This is supported by ${ }^{31} \mathrm{P}$ NMR results for $\mathrm{Ca}$ phosphate glass that show a great majority of $Q^{2}$ groups in the metaphosphate composition [14]. Previous studies of calcium metaphosphate glass have failed to agree on the coordination of the calcium with oxygen, values vary between 6 and $8[1,15,16,3]$. This is mainly due to the difficulty in distinguishing the $\mathrm{Ca}-\mathrm{O}$ correlation from others in the diffraction data.

Previous modelling studies of phosphate glasses have used molecular dynamics (MD) and, reverse Monte Carlo (RMC) modelling. Such studies of glass structure can provide heuristic support for experimental results by providing a valid threedimensional model structure, and can use a range of data to help reveal structural features not easily discerned from isolated data sets. RMC gives excellent agreement with diffraction data, but does not always produce smooth short range order, whereas the contrary can be said of $\mathrm{MD}$, due to the different approaches used in the two methods. MD modelling of phosphate glass has been very limited, being reported only for $\mathrm{Li}$ [17], $\mathrm{Na}$ [18], $\mathrm{Mg}, \mathrm{Zn}$ and $\mathrm{Pb}$ [19], and $\mathrm{Tb}$ [20] metaphosphate glasses. RMC modelling has been more common, being reported for $\mathrm{Zn}, \mathrm{Sr}, \mathrm{Ba}, \mathrm{Na}$ and $\mathrm{K}$ [21], Li [22], Mg and Co [23], K [24], Zn [25-27] and lanthanides $[28,29]$. There has only been one reported model for Ca metaphosphate glass in 1987, [21], being a preliminary RMC study which used only $\mathrm{x}$-ray diffraction data.

In this study neutron diffraction data reported in [30] and new x-ray diffraction data is used to obtain more robust and detailed structural information. Reverse Monte Carlo modelling of both $\mathrm{x}$-ray and neutron diffraction data has been used to help identify and distinguish the different correlations. The model is constructed based on known structural characteristics of phosphate networks, such as the geometry of the basic phosphate unit, and then refined to match the experimental diffraction data. The individual pairwise correlation functions may then be separated and quantitatively identified. This approach of combining computer simulations with more than one set of experimental data helps to avoid misinterpretation of data and has enabled more structural information to be extracted than is possible from any one technique alone.

\section{Method}

The melt-quenched glass sample was prepared using calcium carbonate $\left(\mathrm{CaCO}_{3}, 99+\%, \mathrm{BDH}\right)$ and phosphorus pentoxide $\left(\mathrm{P}_{2} \mathrm{O}_{5}, 97 \%, \mathrm{BDH}\right)$. The precursors were heated in a $\mathrm{Pt} / 10 \% \mathrm{Rh}$ crucible (71040, Johnson Matthey) at $300^{\circ} \mathrm{C}$ for $30 \mathrm{~min}$, then raised to $600{ }^{\circ} \mathrm{C}$ for $30 \mathrm{~min}$ and then $1100^{\circ} \mathrm{C}$ for $60 \mathrm{~min}$, using a Carbolite furnace (RHF 1500, UK). The molten glass was then poured into a graphite mould that had been heated to $370^{\circ} \mathrm{C}$ and left to cool to room temperature [30].

The density of the sample was determined by helium pycnometry using a Quantachrome Multipycnometer. The sample has a density of $2.61 \pm 0.05 \mathrm{~g} \mathrm{~cm}^{-3}$, equivalent to a number density of 0.071 atoms $\AA^{-3}$.

\subsection{X-ray diffraction}

The x-ray diffraction data was collected on Station 9.1 of the Synchrotron Radiation Source (SRS), Daresbury Laboratory. The finely powdered samples were enclosed inside a $0.5 \mathrm{~mm}$ thick circular metal annulus with Kapton windows and mounted in $\theta / 2 \theta$ transmission geometry. The wavelength was set at $\lambda=0.4858 \AA$ (calibrated using the K-edge of an Ag foil); this wavelength provides data to a high value of momentum transfer $\left(Q_{\max } \sim 23 \AA^{-1}\right.$ where $\left.Q=4 \pi \sin \theta / \lambda\right)$.

The data was then analysed using software written inhouse. The first stage is the application of corrections for the polarization of the $\mathrm{x}$-ray beam, the variation in sample thickness with incident angle, and background scattering. Corrections for the absorption, Compton scattering, the selfscattering and the sharpening function are then made. The resultant scattering intensity, $i(Q)$, can reveal structural information via a Fourier transform to obtain the total pair correlation function, as in (1).

$$
T_{X}(r)=2 \pi^{2} \rho_{N} r+\int_{Q_{\min }}^{Q_{\max }} M(Q) Q i_{X}(Q) \sin (Q r) \mathrm{d} Q
$$

where $r$ is the atomic separation between atoms, $\rho_{N}$ is bulk number density and $M(Q)$ is a window function, applied to reduce the Fourier transform termination artefacts that arise from the finite range of $Q$. Here a Hanning window function has been used.

In order to obtain the structural information directly from the experimental data, each possible pairwise combination of elements $i$ and $j$ is represented by a pair correlation function $p_{i j}(r)$ that is then fitted to the data. The $Q$ space simulation of each pair correlation function $p_{i j}(Q)$ is generated using (2).

$$
p_{i j}(Q)=N_{i j} \omega_{i j} \sin Q r_{i j} \exp \left[-0.5 Q^{2} \sigma_{i j}^{2}\right]\left(c_{j} Q r_{i j}\right)^{-1} .
$$

The sum of these $p_{i j}(Q)$ is equivalent to the $i_{X}(Q)$ in (1) and is Fourier transformed using (1) for comparison to the experimental real-space data $T_{X}(r)$, having been subjected to exactly the same Fourier transform effects.

The parameters in (2) are the coordination number $N_{i j}$, the atomic separation $r_{i j}$, and the disorder factor $\sigma_{i j}$. These are varied in the fitting procedure. The parameter $c_{j}$ is the concentration of atom type $j$ and $\omega_{i j}$ is the weighting function 
that accounts for the variation in scattering strength of different atom types, as defined in (3).

$$
\omega_{i j}=\frac{\left(2-\delta_{i j}\right) c_{i} c_{j} f_{i}(Q) f_{j}(Q)}{[f(\bar{Q})]^{2}} .
$$

\subsection{Neutron diffraction}

The neutron diffraction data [30] was collected on the GEM diffractometer on the ISIS spallation neutron source at the Rutherford Appleton Laboratory, UK. Time-of-flight data was collected over a wide range of $Q$ (up to $40 \AA^{-1}$ ). The samples were in the form of $8 \mathrm{~mm}$ diameter rods therefore no container was required. The program GUDRUN was used to reduce and correct the data [31].

The principles of neutron diffraction have much in common with those for $\mathrm{x}$-rays, and equations of the same form are used in the analysis. A key difference originates from the neutrons interacting with nuclei as scattering centres rather than electron clouds as for x-rays. In neutron diffraction the real-space total correlation function $T(r)$ is given by (4), where $b_{i}$ is the scattering length that describes how strongly the target nuclei scatter neutrons. The value of $b_{i}$ used for a given element is an average over the natural abundance of isotopes for that element. Here a Lorch window function is used.

$$
\begin{aligned}
T_{N}(r) & =4 \pi \rho_{N} r\left(\sum_{i} c_{i} b_{i}\right)^{2} \\
+ & \stackrel{2}{\pi} \int_{Q_{\min }}^{Q_{\max }} M(Q) Q i_{N}(Q) \sin (Q r) \mathrm{d} Q .
\end{aligned}
$$

Structural information is then obtained from the experimental data using the same method as for the x-ray diffraction data. Each type of atom pair is modelled by a pair correlation function as defined in (2). For neutron diffraction the weighting factors are defined in (5).

$$
\omega_{i j}=\left(2-\delta_{i j}\right) c_{i} c_{j} b_{i} b_{j}
$$

The accuracy of information obtained from fitting pair correlation functions depends on correctly assigning the atom types to $i$ and $j$ for all the peaks $p_{i j}(r)$, including those that overlap. Accurate results can be obtained once all peaks are identified and accounted for. The fitting was then optimized by using a nonlinear least squares fitting algorithm to find the parameters $R_{i j}, N_{i j}$ and $\sigma_{i j}$ which give best agreement with experiment.

\subsection{Reverse Monte Carlo modelling}

Reverse Monte Carlo is a method for structural modelling which makes it possible to generate three-dimensional models that are consistent with experimental data. RMC is a useful technique as the models developed agree quantitatively with all available experimental data as well as with constraints that represent our existing knowledge of the system, for example: density, atomic radii, approximate bond lengths [32].

A model is defined as a set of $N$ virtual atoms in a box at the density corresponding to that of the real material.
The diffraction pattern is calculated based on the current configuration and then compared to the experimental data. A random walk approach is taken in search of a set of atom positions that is consistent with experimental data [33]. The partial structure factors, $i_{i j}(Q)$, are calculated using (6), from these the total structure factor, $i(Q)$, is calculated using (7), where $g_{i j}(r)$ are the partial pair distribution functions.

$$
\begin{gathered}
Q i_{i j}(Q)=4 \pi \rho \int_{0}^{\infty} r g_{i j}(r) \sin (Q r) \mathrm{d} r \\
i(Q)=\sum_{i j} c_{i} c_{j} b_{i} b_{j} i_{i j}(Q) .
\end{gathered}
$$

The standard RMCA program has been used to model the atomic structure against both $\mathrm{x}$-ray and neutron diffraction data [32]. The route taken to build the model can affect its success so care is taken to ensure the result is in agreement with known information about atomic structure. Here the following technique has been used to construct a model of 1080 atoms.

(1) A random configuration of $240 \mathrm{P}$ atoms was generated. Then chains of $\mathrm{P}$ atoms were created by constraining the $\mathrm{P}-\mathrm{P}$ coordination number, $N_{\mathrm{P}-\mathrm{P}}=2$.

(2) 240 bridging oxygen atoms $\left(\mathrm{O}_{\mathrm{b}}\right)$ were added at the midpoints of nearest neighbour $\mathrm{P}-\mathrm{P}$ pairs.

(3) 480 non-bridging oxygen atoms $\left(\mathrm{O}_{\mathrm{nb}}\right)$ were added randomly.

(4) A metaphosphate structure was obtained using the constraints $N_{\mathrm{O}_{\mathrm{b}}-\mathrm{P}}=2, N_{\mathrm{P}-\mathrm{O}_{\mathrm{b}}}=2, N_{\mathrm{O}_{\mathrm{nb}}-\mathrm{P}}=1$, $N_{\mathrm{P}-\mathrm{O}_{\mathrm{nb}}}=2$.

(5) Constraints were also applied to the bond angles so that they were centred on $\theta_{\mathrm{O}-\mathrm{P}-\mathrm{O}}=109^{\circ}$ and $\theta_{\mathrm{P}-\mathrm{O}_{\mathrm{b}}-\mathrm{P}}=$ $135^{\circ}$.

(6) The 120 calcium atoms were then added randomly and constraints were made against non-physical solutions such as $N_{\mathrm{Ca}-\mathrm{O}}=0,1,2,3$ or 4 .

(7) The RMC method was then used to fit the model to the experimental $i(Q)$, with $\Delta Q=0.05 \AA^{-1}$, and $Q_{\max }=$ $22.9 \AA^{-1}$ and $40 \AA^{-1}$ for $\mathrm{x}$-ray and neutron diffraction data respectively.

RMC uses distance parameters to define the distance of closest approach $R_{\min }$ (called cut offs), and coordination constraints are defined using a distance representing a maximum in the nearest neighbour separation for the given atom pairs, $R_{\max }$. The distance parameters $R_{\min }$ and $R_{\max }$ used in the construction of the model were obtained from existing knowledge of phosphate glasses [1] and data on phosphate crystal structures from the crystallographic database provided by the STFCs chemical database service (CDS) [34]. The values of $R_{\min }$ and $R_{\max }$ used in the present study are shown in table 2 .

\section{Results}

\subsection{XRD and ND}

The experimental $\mathrm{x}$-ray and neutron diffraction data is shown in $Q$-space in figure 1 and in real space in figures 2 and 3 . Table 1 


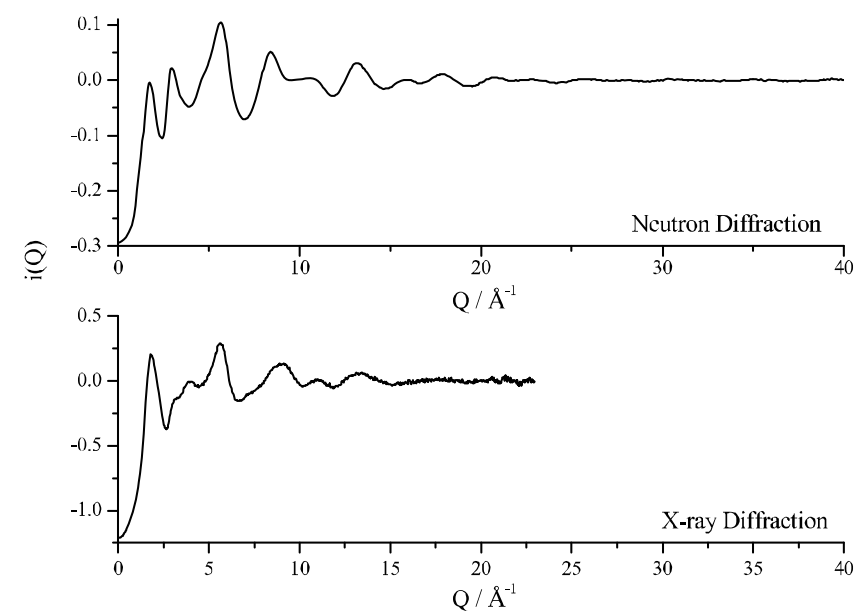

Figure 1. The $Q$-space interference function, $i(Q)$ obtained from neutron diffraction (top [30]) and $\mathrm{x}$-ray diffraction (bottom).

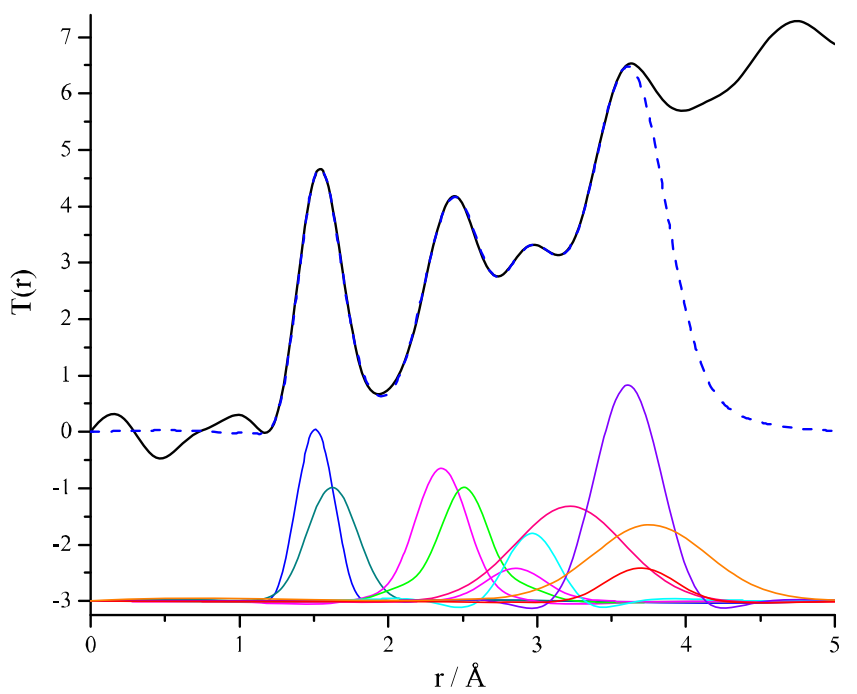

Figure 2. The total pair distribution function, $T(r)$, (solid line) together with fit (dashed line) from the $\mathrm{x}$-ray diffraction. The individual pair distribution functions are also shown off-set by -3 , the final peak is fitted as a background.

shows the sequence of interatomic correlations (between atom types $i$ and $j$ ) which was used to fit the x-ray and neutron diffraction data, and the values obtained for the structural parameters (distance $R_{i j}$, number of neighbouring atoms $N_{i j}$, and standard deviation in distance $\sigma_{i j}$ ). The individual interatomic correlations, $p_{i j}(r)$, are also shown in figures 2 and 3 where they are off-set for clarity. An additional peak is visible at high $R$ that is not reported in the table as it is not representative of a real feature, it is used to reduce the effect of high $R$ correlations on the fitting of the $\mathrm{Ca}-\mathrm{Ca}$ correlation.

The XRD and ND data were fitted separately with the same sequence of interatomic correlations. Table 1 shows the highly consistent fitting parameters obtained, with only one difference exceeding $\pm 0.02 \AA$ in $R$. This larger difference in the value of $R$ for the $\mathrm{O}-\mathrm{O}$ correlation is understandable considering the low weighting this correlation has in XRD.

The first interatomic correlation is $\mathrm{P}-\mathrm{O}$ at an average distance of $1.55 \AA$. In phosphates this is split into shorter

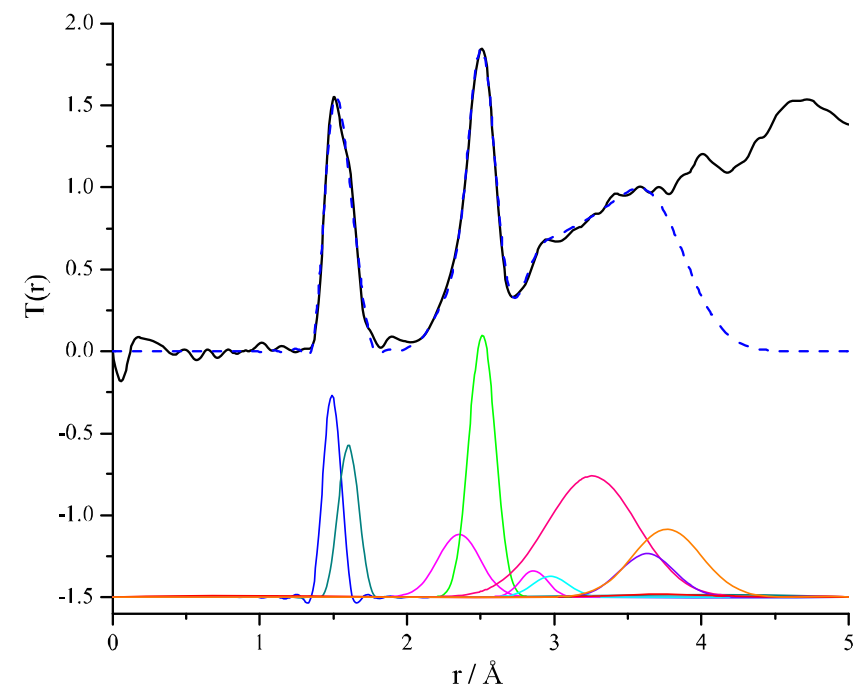

Figure 3. The total pair distribution function, $T(r)$, (solid line) together with fit (dashed line) from the neutron diffraction data. The individual pair distribution functions are also shown off-set by -1.5 , the final peak is fitted as a background.

Table 1. Structural parameters derived from fitting $T(r)$ to x-ray and neutron diffraction data.

\begin{tabular}{|c|c|c|c|c|c|c|}
\hline \multirow[b]{2}{*}{ Correlation } & \multicolumn{3}{|c|}{ X-ray diffraction } & \multicolumn{3}{|c|}{ Neutron diffraction } \\
\hline & $\begin{array}{l}R(\AA) \\
( \pm 0.02)\end{array}$ & $\begin{array}{l}N \\
( \pm 0.2)\end{array}$ & $\begin{array}{l}\sigma(\AA) \\
( \pm 0.01)\end{array}$ & $\begin{array}{l}R(\AA) \\
( \pm 0.02)\end{array}$ & $\begin{array}{l}N \\
( \pm 0.2)\end{array}$ & $\begin{array}{l}\sigma(\AA) \\
( \pm 0.01)\end{array}$ \\
\hline $\mathrm{P}-\mathrm{O}_{\mathrm{nb}}$ & 1.51 & 1.9 & 0.03 & 1.49 & 2.0 & 0.02 \\
\hline $\mathrm{P}-\mathrm{O}_{\mathrm{b}}$ & 1.62 & 1.9 & 0.12 & 1.60 & 1.9 & 0.04 \\
\hline $\mathrm{Ca}-\mathrm{O}$ & 2.36 & 5.2 & 0.14 & 2.35 & 5.2 & 0.14 \\
\hline $\mathrm{O} \cdots \mathrm{O}$ & 2.51 & 4.0 & 0.10 & 2.51 & 4.0 & 0.07 \\
\hline $\mathrm{Ca}-\mathrm{O}$ & 2.86 & 1.8 & 0.17 & 2.86 & 1.7 & 0.08 \\
\hline $\mathrm{P} \cdots \mathrm{P}$ & 2.97 & 2.0 & 0.14 & 2.97 & 2.0 & 0.11 \\
\hline $\mathrm{O} \cdots \mathrm{O}$ & 3.22 & 8.2 & 0.31 & 3.26 & 8.2 & 0.30 \\
\hline $\mathrm{P} \cdots \mathrm{Ca}$ & 3.61 & 4.3 & 0.22 & 3.63 & 4.2 & 0.18 \\
\hline $\mathrm{Ca} \cdots \mathrm{Ca}$ & 3.70 & 2.1 & 0.23 & 3.70 & 2.1 & 0.32 \\
\hline
\end{tabular}

bonds to non-bridging oxygen atoms $\left(\mathrm{O}_{\mathrm{nb}}\right)$ and longer bonds to bridging oxygen atoms $\left(\mathrm{O}_{\mathrm{b}}\right)$. This split is clearly seen as a shoulder at high $r$ in neutron diffraction, but discernible only as asymmetry in XRD. The fit results show $N_{\mathrm{P}-\mathrm{O}}=3.9$, agreeing within uncertainty with the value of $N_{\mathrm{P}-\mathrm{O}}=4$ expected for phosphate tetrahedra, and this is split between two $\mathrm{O}_{\mathrm{nb}}$ and two $\mathrm{O}_{\mathrm{b}}$ as expected for a metaphosphate glass. The observed average distances of 1.50 and $1.61 \AA$ for $\mathrm{P}-\mathrm{O}_{\mathrm{nb}}$ and $\mathrm{P}-\mathrm{O}_{\mathrm{b}}$ correlations are in good agreement with results for diffraction of other metaphosphate glasses [35].

On the basis of the $\mathrm{P}-\mathrm{O}$ coordination, two related correlations can be confidently defined. Firstly the O-P-O correlations due to phosphate tetrahedra (with tetrahedral $\mathrm{O}-$ $\mathrm{P}-\mathrm{O}$ angle of $\sim 109^{\circ}$ ) would have a distance of $\sim 2.54 \AA$ and an average coordination $N_{\mathrm{O}-\mathrm{O}}$ of 4 (average of two $\mathrm{O}_{\mathrm{nb}}$ with $N=3$ and one $\mathrm{O}_{\mathrm{b}}$ with $N=6$ ). Secondly the P-O-P correlations due to chains of phosphate tetrahedra (with typical $\mathrm{P}-\mathrm{O}-\mathrm{P}$ angle of $\sim 135^{\circ}$ [36]) would have a distance of $2.99 \AA$ and a coordination of two. The results of fitting are in good agreement with these expectations. They are also in agreement with results for diffraction of other metaphosphate glasses [35]. 


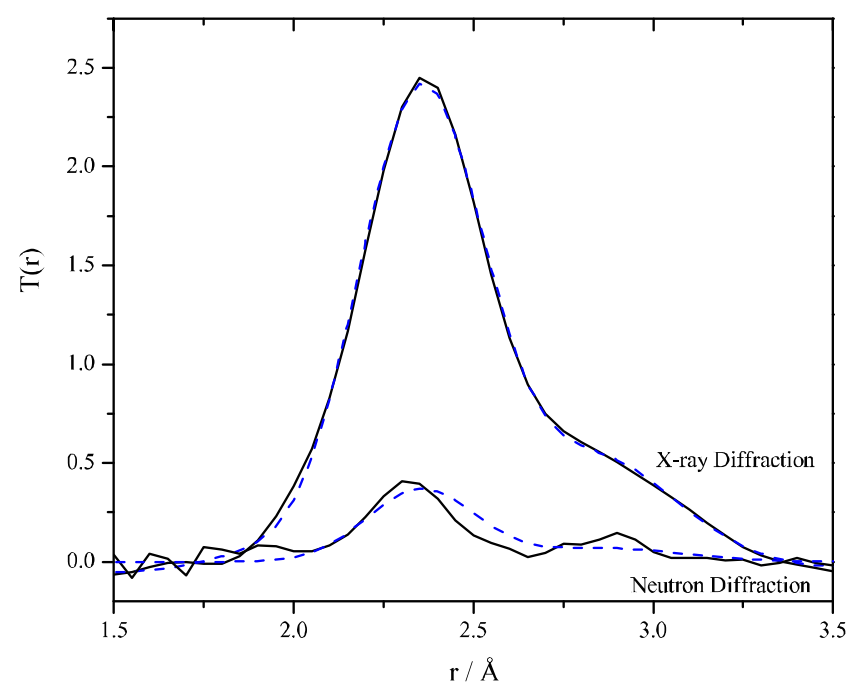

Figure 4. The individual pair distribution function for $\mathrm{Ca}-\mathrm{O}$ extracted from the $T(r)$ by subtracting the fit for all the other correlations, demonstrating the broad spread in bond length and hence the need to fit it with two peaks.

A second type of cation-oxygen bond is present in the structure, $\mathrm{Ca}-\mathrm{O}$, and this gives the second shortest correlation. These bonds are typically $\sim 2.4 \AA$ in length, but they can show a wide spread due to flexibility in the coordination of $\mathrm{Ca}$ [37]. Due to the length of $\mathrm{Ca}-\mathrm{O}$ bonds, the $\mathrm{Ca}-\mathrm{O}$ correlation overlaps with the O-P-O correlation at $2.51 \AA$. This is visible as a shoulder on the low $r$ side of the peak in neutron diffraction, and as an asymmetry to low $\mathrm{r}$ in the $\mathrm{x}$-ray diffraction. The difficulty lies in identifying $\mathrm{Ca}-\mathrm{O}$ correlations which may extend under the $\mathrm{O}-\mathrm{P}-\mathrm{O}$ correlation and up to distances as high as $3 \AA$. Figure 4 shows the $\mathrm{Ca}-\mathrm{O}$ correlation extracted from the experimental data by subtracting the fit of all the other correlations. It shows a wide distribution in bond distance with a second feature at higher $r$. This requires allowing an additional peak in the fitting between the O-P-O and $\mathrm{P}-\mathrm{O}-\mathrm{P}$ correlations to fit the residual correlations hidden beneath them.

Considering the role of $\mathrm{Ca}$ in the structure, there are an additional three correlations which can be safely predicted from the $\mathrm{Ca}-\mathrm{O}$ correlation. These are the $\mathrm{O}-\mathrm{Ca}-\mathrm{O}, \mathrm{Ca}-\mathrm{O}-$ $\mathrm{P}$ and the $\mathrm{Ca}-\mathrm{O}-\mathrm{Ca}$ correlations. The $\mathrm{O}-\mathrm{Ca}-\mathrm{O}$ correlations are due to polyhedral units of $\mathrm{Ca}$ coordinated by $N$ oxygen atoms, referred to as $\mathrm{CaO}_{N}$. The observed $\mathrm{O}-\mathrm{Ca}-\mathrm{O}$ distance of $\sim 3.24 \AA$ is in agreement with data from the Chemical Database Service [34] and the coordination of $\sim 8.2$ is close to the value of 8 expected for an oxygen which is part of two $\mathrm{CaO}_{6}$ octahedra and has nearest neighbours with four oxygen atoms from each. From the correlation distance an $\mathrm{O}-\mathrm{Ca}-$ $\mathrm{O}$ bond angle of $81.6^{\circ}$ is calculated which is close to that of $90^{\circ}$ for an octahedron and is in agreement with the capped trigonal prism structure described by Rothammel et al [16] for Ca metaphosphate crystal.

The two remaining correlations are $\mathrm{P}-\mathrm{O}-\mathrm{Ca}$ and $\mathrm{Ca}-$ $\mathrm{O}-\mathrm{Ca}$. The distances of these are difficult to estimate, but will be longer than $\mathrm{P}-\mathrm{O}-\mathrm{P}$ distances due to the longer $\mathrm{Ca}-\mathrm{O}$ bonds. The increasing number of overlapping correlations at
Table 2. Structural parameters derived from the RMC fitting to $\mathrm{x}$-ray and neutron diffraction data. Also listed are the cut offs used in the development of the model.

\begin{tabular}{lllll} 
& & \multicolumn{3}{c}{ Cut offs } \\
Correlation & $R(\AA)( \pm 0.03)$ & $N( \pm 0.3)$ & Min $R(\AA)$ & $\operatorname{Max} R(\AA)$ \\
\cline { 3 - 5 }$-\mathrm{O}_{\mathrm{b}}$ & 1.61 & 2.00 & 1.48 & 1.80 \\
$\mathrm{P}-\mathrm{O}_{\mathrm{nb}}$ & 1.53 & 1.99 & 1.36 & 1.80 \\
$\mathrm{Ca}-\mathrm{O}_{\mathrm{nb}}$ & 2.41 & 4.97 & 2.05 & 2.70 \\
$\mathrm{O}_{\mathrm{b}} \cdots \mathrm{O}_{\mathrm{b}}$ & 2.52 & 1.85 & 2.20 & 2.85 \\
$\mathrm{O}_{\mathrm{b}} \cdots \mathrm{O}_{\mathrm{nb}}$ & 2.51 & 3.97 & 2.20 & 2.85 \\
$\mathrm{O}_{\mathrm{nb}} \cdots \mathrm{O}_{\mathrm{nb}}$ & 2.51 & 2.07 & 2.20 & 2.85 \\
$\mathrm{Ca}-\mathrm{O}_{\mathrm{nb}}$ & 2.99 & 0.66 & 2.70 & 3.20 \\
$\mathrm{P} \cdots \mathrm{P}$ & 2.93 & 2.00 & 2.75 & 3.20 \\
$\mathrm{O}_{\mathrm{nb}} \cdots \mathrm{O}_{\mathrm{nb}}$ & 3.35 & 3.85 & 2.85 & 3.80 \\
$\mathrm{P} \cdots \mathrm{Ca}$ & 3.64 & 2.80 & 3.20 & 4.20 \\
$\mathrm{Ca} \cdots \mathrm{Ca}$ & 3.66 & 1.78 & 3.20 & 4.20 \\
& & & &
\end{tabular}

the longer distances also makes the fitting less reliable. For these reasons the correlations are not often quoted in previous work; however, the use of a combination of techniques makes it possible to identify them here. The $\mathrm{P}-\mathrm{O}-\mathrm{Ca}$ correlation is at an average distance of $3.62 \AA$. Comparing this with the typical $\mathrm{P}-\mathrm{O}$ and $\mathrm{Ca}-\mathrm{O}$ bond lengths, this indicates a $\mathrm{P}-\mathrm{O}-\mathrm{Ca}$ bond angle between $105^{\circ}$ and $140^{\circ}$, a reasonable result for a modifier cation in a phosphate network. If it is assumed that the $\mathrm{Ca}$ is only bonded to the $\mathrm{O}_{\mathrm{nb}}$, then the $\mathrm{P}-\mathrm{Ca}$ coordination number of 4.2 implies each $\mathrm{O}_{\mathrm{nb}}$ is bonded to two $\mathrm{Ca}$-oxygen polyhedral units. These results are comparable to the crystal structure in which the average distance between $\mathrm{P}$ and $\mathrm{Ca}$ is $3.56 \AA$ and the $\mathrm{P}-\mathrm{Ca}$ coordination number is 3.5 [16]. The $\mathrm{Ca}-\mathrm{Ca}$ distance of $3.70 \AA$ is comparable to the crystal structure, however, the crystal also has longer $\mathrm{Ca}-\mathrm{Ca}$ distances extending up to $4.7 \AA$. Such longer $\mathrm{Ca}-\mathrm{Ca}$ distances are likely to have been masked in the glass diffraction data by overlapping correlations at distances beyond $3.5 \AA$. Taking into account only the shorter $\mathrm{Ca}-\mathrm{Ca}$ distances less than $4 \AA$, the $\mathrm{Ca}-\mathrm{Ca}$ coordination of 2 also matches well with the crystal data.

\subsection{RMC modelling}

Figure 5 shows the result obtained for RMC modelling of the ND and XRD data in $Q$ space. As expected, due to the RMC method, a very good fit is obtained. The RMC model obtained is illustrated in figure 6 . This model consists of chains of phosphate tetrahedra, as expected for a realistic metaphosphate structure, and was achieved by use of suitable constraints in RMC modelling, discussed in section 2. By analysing the model the individual pair correlation functions were isolated and structural parameters were found for each. These are listed in table 2 where $R$ is the average bond length within the first nearest neighbour peak (defined by the interval between $R_{\min }$ and $R_{\max }$ in table 2) and $N$ corresponds to the area of the peak. Note that these correlations of atom types $i$ and $j$ follow the same sequence as discussed in the peak fitting analysis presented above, which provides a selfconsistent confirmation that the assignment of correlations is sound. Figure 7 shows the interatomic correlations generated from the coordinates of the model. These are noisier than the peaks used in the peak fitting because they come from the 

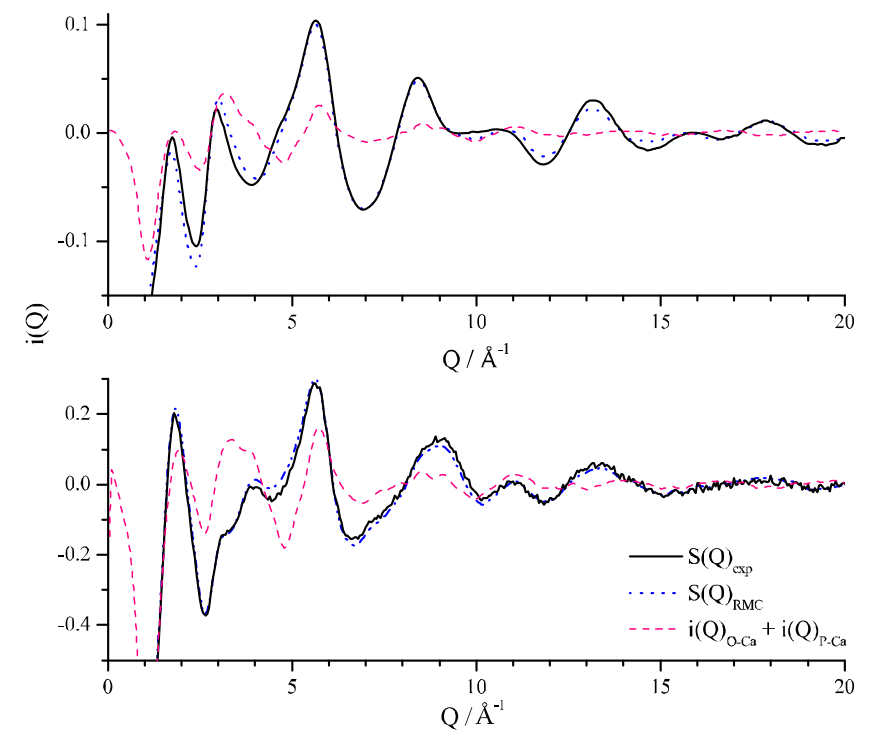

Figure 5. RMC fit to experimental $i(Q)$ : (top) RMC compared to neutron diffraction data, (bottom) RMC compared to $\mathrm{x}$-ray diffraction data.

positions of a relatively small number of model atoms, rather than average structural parameters used in peak fitting. In particular, the $\mathrm{P}-\mathrm{O}$ correlation has a sharp peak before its $R_{\max }$ value of $1.8 \AA$ that comes from an especially tight constraint. This effect is acceptable in RMC because the constraint is modelling a feature of phosphate glasses that is known with great confidence.

The model can be analysed to obtain some additional structural information. The phosphate network and the $\mathrm{PO}_{4}$ tetrahedra are well-defined due to the bond angle constraints used, as shown in figure 8 . The network is $100 \% Q^{2}$ due to the connectivity constraint used in model building. This constraint was motivated by NMR results [30] which show $Q^{2}$ units can join to form (closed) rings or (open) chains. The number of three-member rings in the model is only ten, so over $80 \%$ of

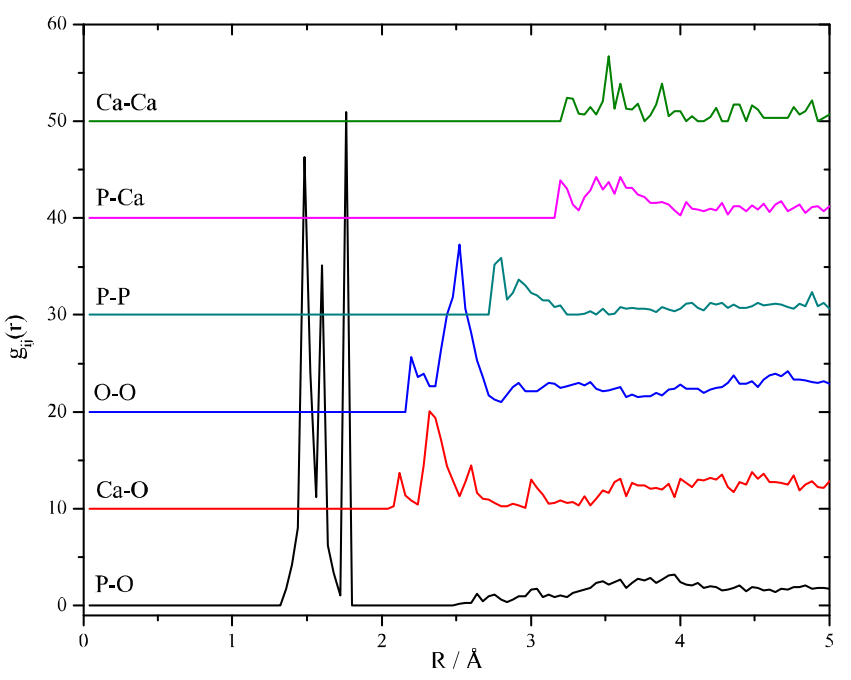

Figure 7. The pair correlations from the RMC fit to experimental data. The $\mathrm{P}-\mathrm{O}, \mathrm{Ca}-\mathrm{O}$ and $\mathrm{O}-\mathrm{O}$ correlations are the sum from $\mathrm{O}_{\mathrm{b}}$ and $\mathrm{O}_{\mathrm{nb}}$. Each correlation is off-set by an additional 10 units.

the $Q^{2}$ tetrahedra are in chains, and inspection of the model showed there were two large fragments.

The $\mathrm{Ca}-\mathrm{O}$ coordination is an interesting result, because this was only constrained to be $N \geqslant 5$ in the modelling (based on $\mathrm{Ca}$ coordination less than 5 being relatively unknown [38]). The $\mathrm{Ca}-\mathrm{O}$ correlation in the model shows a broad distribution with most distances around $2.35 \AA$ and some up to $3.0 \AA$, as was also seen in the peak fitting of $\mathrm{x}$-ray and neutron diffraction data. The $\mathrm{Ca}-\mathrm{O}$ coordination of 5.6 is less than that found by diffraction, but $55 \%$ of the Ca atoms have a coordination of 6 or 7 , as shown in figure 9 .

The $\mathrm{O}-\mathrm{Ca}-\mathrm{O}$ bond angle has been analysed and is shown in figure 8. It shows a distribution similar to that expected for 6 coordinated $\mathrm{Ca}$, with a peak around $90^{\circ}$ associated with adjacent $\mathrm{O}$ in the structural unit, and a second peak at a higher angle from $\mathrm{O}$ on the opposite sides of the structural unit. A regular octahedron would have peaks at $90^{\circ}$ and $180^{\circ}$, and the
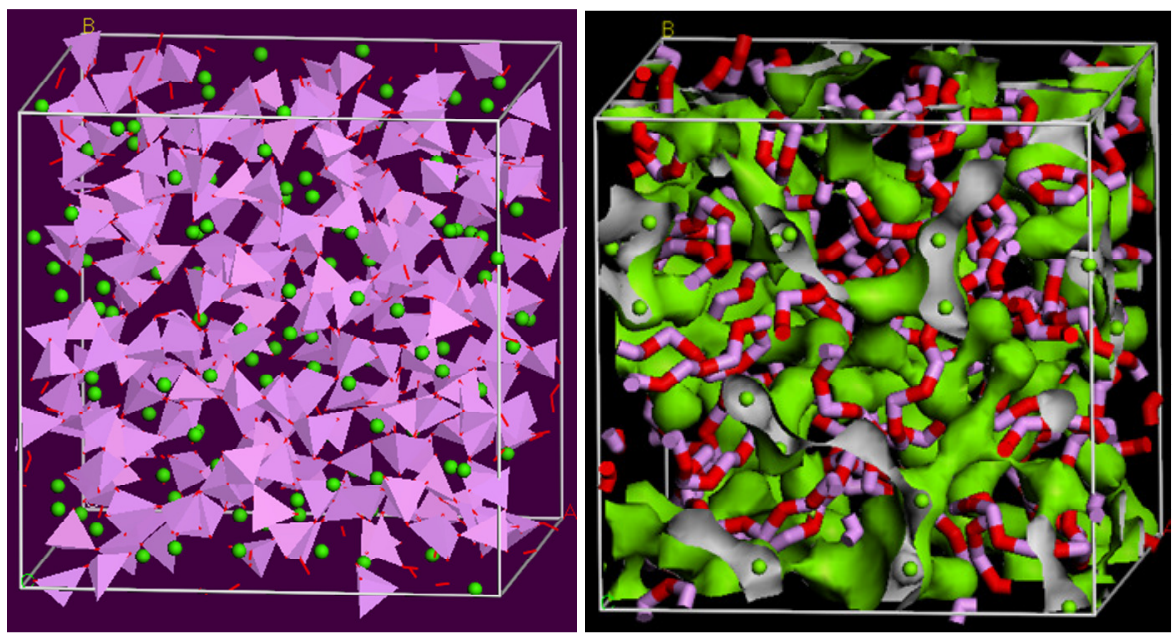

Figure 6. The RMC model. The left image shows the phosphate units as tetrahedra (in the electronic version these are purple) and the calcium ions as isolated spheres (green). The right image shows the $-\mathrm{P}-\mathrm{O}-\mathrm{P}-\mathrm{O}-$ backbone (purple and red chain) and the Ca clusters as a surface (green). 


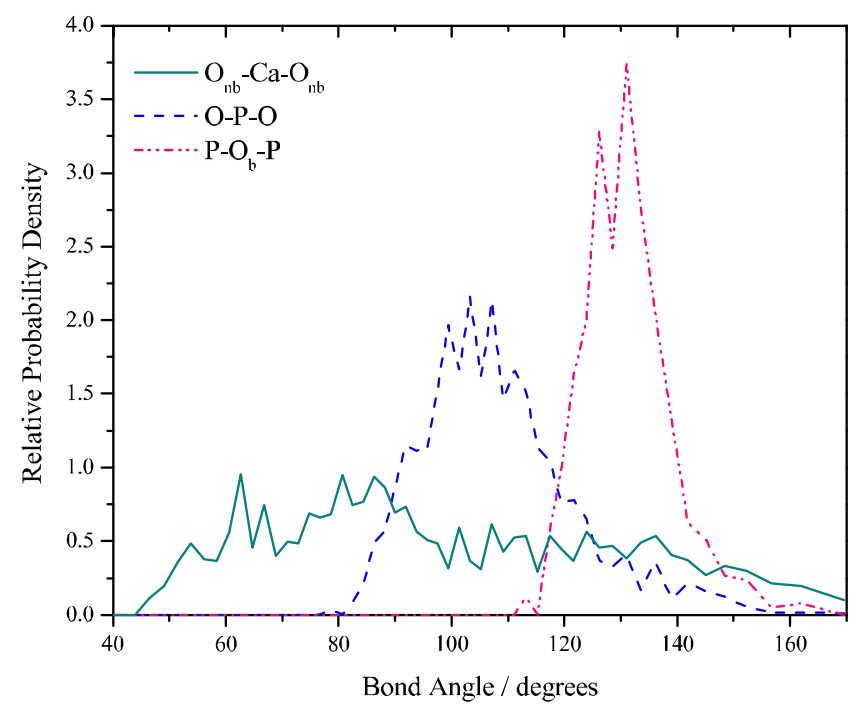

Figure 8. The RMC models bond angle distributions for $\mathrm{O}_{\mathrm{nb}}-\mathrm{Ca}-\mathrm{O}_{\mathrm{nb}}, \mathrm{P}-\mathrm{O}_{\mathrm{b}}-\mathrm{P}$ and the average of all the $\mathrm{O}-\mathrm{P}-\mathrm{O}$.

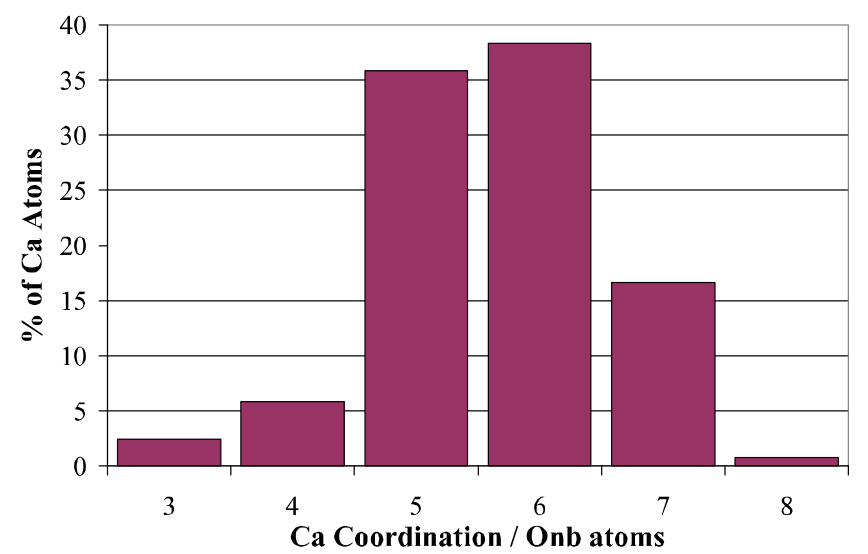

Figure 9. The $\mathrm{Ca}-\mathrm{O}$ coordination distribution from the $\mathrm{RMC}$ model.

broadened nature of the second peak implies a more distorted octahedral unit in the model.

The $\mathrm{P}-\mathrm{Ca}$ correlation distance and coordination number are in agreement with the diffraction results, including the average $\mathrm{P}-\mathrm{O}-\mathrm{Ca}$ bond angle of $127^{\circ}$. The $\mathrm{Ca}-\mathrm{O}-\mathrm{Ca}$ correlation has greater statistical variability, which makes it difficult to extract information concerning the broad distribution in $\mathrm{Ca}-\mathrm{Ca}$ distances discussed earlier. However, the $\mathrm{Ca}-\mathrm{Ca}$ correlation does seem to show a first nearest neighbour peak with average distance of $3.66 \AA$ with coordination number of 1.8 , which supports the $\mathrm{Ca}-\mathrm{Ca}$ peak assignment used in fitting the diffraction data.

\section{Discussion}

For the phosphate network, all the parameters confirm the tetrahedral structure and the $Q^{2}$ speciation as expected for the metaphosphate composition. These parameters are also in agreement with Hoppe's model for the structure of phosphate glasses [12]. A previous NMR study of the same sample indicated $96 \% Q^{2}$ and $4 \% Q^{1}$ [30], and such a distribution would imply a slight increase in the number of $\mathrm{P}-\mathrm{O}_{\mathrm{nb}}$ bonds, with $N_{\mathrm{P}-\mathrm{O}_{\mathrm{nb}}}=2.04$ and $N_{\mathrm{P}-\mathrm{O}_{\mathrm{b}}}=1.96$, but such a small effect, if real, is beyond the level of uncertainty in the present results.

The diffraction experiments have differentiated two $\mathrm{Ca}-\mathrm{O}$ bond lengths, a shorter distance of $\sim 2.36 \AA$ has a coordination of $\sim 5.2$ and a longer distance of $\sim 2.86 \AA$ has a coordination of $\sim 1.8$. Our previous study using ND alone [30] only identified the first correlation as $\mathrm{Ca}-\mathrm{O}$ and the second peak was fitted with another $\mathrm{O}-\mathrm{O}$ correlation but no physical description could be given. Crystallographic data has shown the longer $\mathrm{Ca}-\mathrm{O}$ bond lengths exist in crystals and it is commonly found for calcium in oxide structures to have oxygen atoms at longer distances [34]. Such a two-peak fitting of cation oxygen correlations has previously been used in diffraction studies of various phosphate and silicate glasses [39], and in particular in zinc and magnesium metaphosphates [40], lanthanum metaphosphate [41] and potassium phosphate [24]. Molecular dynamics models of calcium silicate [42] and calcium aluminate [43] glasses also show that $\mathrm{Ca}-\mathrm{O}$ nearest neighbour peak has an asymmetric shape with shoulder extending to $\sim 3 \AA$.

The total $\mathrm{Ca}-\mathrm{O}$ coordination number of $\sim 7.0$ found here is in agreement with Hoppe et al [15]. This coordination can relate to three possible types of polyhedral structures: the pentagonal bipyramid, the capped trigonal prism, and the capped octahedron. Calcium metaphosphate crystal of the same composition has the capped trigonal prism structure [16]. This type of structure is similar to a distorted octahedron, but with an additional atom. The distribution of $\mathrm{Ca}-\mathrm{O}$ bond lengths from diffraction can be considered in relation to the bond valence of $\mathrm{Ca}$. This is the way in which the total valence of 2 for $\mathrm{Ca}, v_{\mathrm{tot}}=2$, is distributed among the $N_{i j} \mathrm{Ca}-\mathrm{O}$ bonds of length $R_{i j}$. The valence associated with an individual $\mathrm{Ca}-\mathrm{O}$ bond, $v_{\mathrm{Ca}-\mathrm{O}}$, is given by (8) [44].

$$
v_{\mathrm{Ca}-\mathrm{O}}=\exp \left(\frac{1.967 \AA-R_{\mathrm{Ca}-\mathrm{O}}}{0.37 \AA}\right) .
$$

Applying this to the diffraction results gives 5.2 bonds of length $2.36 \AA$ and bond valence $v_{\mathrm{Ca}-\mathrm{O}}=0.35$, and 1.8 bonds of length $2.86 \AA$ and bond valence $v_{\mathrm{Ca}-\mathrm{O}}=0.09$, with a total bond valence of 1.96 as expected for a $\mathrm{Ca}^{2+}$ cation.

The coordination of $\mathrm{O}_{\mathrm{nb}}$ to $\mathrm{Ca}$ can be considered by looking at the $\mathrm{Ca}-\mathrm{O}$ coordination number from diffraction. The $\mathrm{Ca}-\mathrm{O}$ coordination number can be converted into the $\mathrm{O}-$ Ca coordination using the relation $c_{i} N_{i j}=c_{j} N_{j i}$ (derived from (2)), and this gives an average value of $\sim 1.17$ for all oxygen atoms. It is assumed that the $\mathrm{O}_{\mathrm{b}}$ have zero coordination with $\mathrm{Ca}$ as the repulsion from two $\mathrm{P}^{5+}$ atoms bonded to the $\mathrm{O}_{\mathrm{b}}$ would make it energetically unfavourable to also be bonded to a $\mathrm{Ca}^{2+}$. Thus, since the $\mathrm{O}_{\mathrm{b}}$ are not coordinated to $\mathrm{Ca}$, the average $\mathrm{O}_{\mathrm{nb}}$ coordination to $\mathrm{Ca}$ will be $\sim 1.75$, which means that approximately three quarters of $\mathrm{O}_{\mathrm{nb}}$ are bonded to two $\mathrm{Ca}$ rather than just one $\mathrm{Ca}$. In comparison the $\mathrm{RMC}$ results show the model has an average $\mathrm{O}-\mathrm{Ca}$ coordination number of 1.4 which implies that approximately half of the $\mathrm{O}_{\mathrm{nb}}$ are coordinated to one $\mathrm{Ca}$ and half are coordinated to two $\mathrm{Ca}$. Note that since each $\mathrm{P}$ has two $\mathrm{O}_{\mathrm{nb}}$, the aforementioned result 
implies that each $\mathrm{P}$ should be coordinated to $\sim 3.4 \mathrm{Ca}$. In fact, the $\mathrm{P}$... Ca coordination of $\sim 4.2$ in both the diffraction data and the RMC model is somewhat larger, which may mean that the $\mathrm{P} \cdots \mathrm{Ca}$ nearest neighbour peak has been somewhat overestimated. However, all of these results nevertheless point to a majority of $\mathrm{O}_{\mathrm{nb}}$ being coordinated to two $\mathrm{Ca}$.

With this information, a valence model can be developed. The metaphosphate composition means there are two phosphate units per $\mathrm{Ca}^{2+}$ cation, and hence there are four $\mathrm{O}_{\mathrm{nb}}$ per $\mathrm{Ca}^{2+}$, each with a bond valence of 0.5 , available to form $\mathrm{Ca}-\mathrm{O}$ bonds. A bond valence model for 6 coordinated $\mathrm{Ca}$ was discussed by Hoppe in which two $\mathrm{O}_{\mathrm{nb}}$ each form one $\mathrm{Ca}-\mathrm{O}$ bond with $v_{\mathrm{Ca}-\mathrm{O}}=0.5$, and two $\mathrm{O}_{\mathrm{nb}}$ each form two $\mathrm{Ca}-\mathrm{O}$ bonds, with $v_{\mathrm{Ca}-\mathrm{O}}=0.25$. From (8), the former would have bond lengths of $2.22 \AA$, and the latter would have bond lengths of $2.48 \AA$, and so no long $\mathrm{Ca}-\mathrm{O}$ bonds would be expected. The diffraction results in the present study indicate a $\mathrm{Ca}-\mathrm{O}_{\mathrm{nb}}$ coordination of 7 , requiring 3 out of $4 \mathrm{O}_{\mathrm{nb}}$ to form two $\mathrm{Ca}-\mathrm{O}$ bonds. Again, if the latter had $v_{\mathrm{Ca}-\mathrm{O}}=0.25$, no long $\mathrm{Ca}-\mathrm{O}$ bonds would be expected. A plausible alternative scenario is that two $\mathrm{O}_{\mathrm{nb}}$ each form two $\mathrm{Ca}-\mathrm{O}$ bonds with $v_{\mathrm{Ca}-\mathrm{O}}=0.4$ and $v_{\mathrm{Ca}-\mathrm{O}}=0.1$. From equation (8), the latter would have bond lengths of $2.8 \AA$, so long $\mathrm{Ca}-\mathrm{O}$ bonds would be expected, which is consistent with the diffraction results.

The foregoing discussion has been primarily concerned with short range order, but it is also important to consider medium range order. This is concerned with structural correlations on scales of several nearest neighbour distances. As previously commented, on this scale the phosphate network consists of metaphosphate chains. Figure 6 highlights the 'backbone' of the phosphate chains, i.e. $\mathrm{P}-\mathrm{O}_{\mathrm{b}}-\mathrm{P}-\mathrm{O}_{\mathrm{b}}-\mathrm{P}$. Also as previously commented, many $\mathrm{O}_{\mathrm{nb}}$ are bonded to two $\mathrm{Ca}$, and this creates $\mathrm{Ca}$ clusters, i.e. $\mathrm{Ca}-\mathrm{O}_{\mathrm{nb}}-\mathrm{Ca}-\mathrm{O}_{\mathrm{nb}}-\mathrm{Ca}$. The $\mathrm{Ca}$ clusters can be described in terms of the type of connections between two adjacent $\mathrm{CaO}_{N}$ polyhedra in the cluster, and this enables an estimate of the typical $\mathrm{Ca}-\mathrm{Ca}$ correlation distances involved. If the typical $\mathrm{Ca}-\mathrm{O}_{\mathrm{nb}}$ distance is $R_{\mathrm{Ca}-\mathrm{O}} \sim$ $2.4 \AA$, the distances of neighbouring $\mathrm{Ca}$ will be approximately $\sqrt{ } 2 R_{\mathrm{Ca}-\mathrm{O}} \sim 3.4 \AA$ if $\mathrm{CaO}_{N}$ polyhedra are edge-sharing, and $2 R_{\mathrm{Ca}-\mathrm{O}} \sim 4.8 \AA$ if $\mathrm{CaO}_{N}$ polyhedra are corner-sharing. The information on $\mathrm{Ca}-\mathrm{Ca}$ correlations from diffraction and $\mathrm{RMC}$ results is limited to the first $\mathrm{Ca}-\mathrm{Ca}$ correlations at a distance of $\sim 3.6 \AA$, and these correspond to edge-sharing of $\mathrm{CaO}_{N}$ polyhedra. The Ca clusters can also be described in terms of their shape, but there is no quantitative way to do this. Instead, the clusters have been illustrated visually in figure 6 by defining a surface that encloses all model $\mathrm{Ca}$ atoms which are within $5 \AA$ of each other, a distance which includes both edge-sharing and corner-sharing of $\mathrm{CaO}_{N}$ polyhedra. The appearance of the clusters is somewhat elongated, which is compatible with the presence of phosphate chains.

Another much examined aspect of medium range order in oxide glasses is the first sharp diffraction peak (FSDP), which is the lowest- $Q$ peak in the diffraction pattern $i(Q)$ and is found at $Q=1.8 \AA^{-1}$ in both ND and XRD. The FSDP is frequently considered to be indicative of structural correlations over medium range length scales. For example, the FSDP in rare earth metaphosphate glasses is associated with rare earth-rare earth correlations [28]. The present RMC model enables us to examine the contribution to $i(Q)$ from different interatomic correlations. For $x$-ray diffraction, the two correlations which contribute the most to the shape of the FSDP are $\mathrm{Ca} \cdots \mathrm{P}$ and $\mathrm{Ca}-\mathrm{O}$ correlations, as shown in figure 5 . (For neutron diffraction, the effect is less pronounced due to the different weighting factors, as also shown in figure 5.) Since the $\mathrm{Ca} \cdots \mathrm{P}$ and $\mathrm{Ca}-\mathrm{O}$ correlations are influenced by the spatial relationship between the phosphate backbone $(\mathrm{P}, \mathrm{O})$ and the Ca clusters $(\mathrm{Ca})$, it seems reasonable to say that the FSDP is influenced by the medium range order for the case of calcium metaphosphate glass.

It has been possible by the combination of techniques, to develop a set of structural parameters for calcium metaphosphate glass that agrees with $\mathrm{x}$-ray and neutron diffraction, RMC modelling, and Hoppe's conceptual model. The use of RMC modelling has allowed us to confirm the identity of all the correlations, and therefore obtain more comprehensive structural information. This is especially true in the case of the calcium which has previously been masked by the phosphate network.

\section{Conclusions}

High quality $\mathrm{x}$-ray and neutron diffraction data have been combined with RMC modelling to give structural parameters for calcium metaphosphate glass, including six interatomic correlations up to a distance of $3.6 \AA$. A well-defined metaphosphate structure has been confirmed by first and second neighbour correlations and bond angles within the phosphate network, including two different $\mathrm{P}-\mathrm{O}$ bonds that distinguish bridging and non-bridging oxygen atoms. The combination of techniques has enabled the identification of correlations involving $\mathrm{Ca}$ that overlap with those from the phosphate network, and there are two $\mathrm{Ca}-\mathrm{O}$ correlations, indicating a wide distribution of bond lengths as commonly seen for $\mathrm{Ca}$ in oxide glasses. The calcium is found to be coordinated with seven oxygen atoms, the same number as in calcium metaphosphate crystal, where $\mathrm{Ca}$ has a capped trigonal prism coordination. The coordination of $\mathrm{Ca}$ to only non-bridging oxygen atoms has been demonstrated in the RMC model, and inspection shows that most non-bridging oxygen atoms are coordinated to two $\mathrm{Ca}$. These observations are all consistent with Hoppe's model for the structure of phosphate glasses. Furthermore, the medium range order is revealed to consist of phosphate chains intertwined with apparently elongated clusters of $\mathrm{Ca}$ ions, and the $\mathrm{Ca}-\mathrm{O}$ and $\mathrm{Ca}$... P correlations contribute significantly to the FSDP in $\mathrm{X}-$ ray diffraction.

\section{Acknowledgments}

The authors wish to acknowledge funding from the EPSRC (EP/E006337/1), support and beamtime from the STFC, and the use of the EPSRC Chemical Database Service at Daresbury. 


\section{References}

[1] Brow R K 2000 Review: the structure of simple phosphate glasses J. Non-Cryst. Solids 263 1-28

[2] Matz W, Stachel D and Goremychkin E A 1988 The structure of alkaline-earth meta-phosphate glasses investigated by neutron-diffraction J. Non-Cryst. Solids 101 80-9

[3] Schneider J, Oliveira S L, Nunes L A O, Bonk F and Panepucci H 2005 Short-range structure and cation bonding in calcium-aluminum metaphosphate glasses Inorg. Chem. 44 423-30

[4] Brow R K 1993 Nature of alumina in phosphate-glass. 1. Properties of sodium aluminophosphate glass J. Am. Ceram. Soc. 76 913-8

[5] Hench L L 1991 Bioceramics - from concept to clinic J. Am. Ceram. Soc. 74 1487-510

[6] Abrahams I, Franks K, Hawkes G E, Philippou G, Knowles J, Bodart P and Nunes T $1997 \mathrm{Na}-23, \mathrm{Al}-27$ and P-31 NMR and $\mathrm{x}$-ray powder diffraction study of $\mathrm{Na} / \mathrm{Ca} / \mathrm{Al}$ phosphate glasses and ceramics J. Mater. Chem. 7 1573-80

[7] Karakassides M A 2005 Preparation and structural study of calcium phosphate glasses and glass ceramics for biomedical applications Phys. Chem. Glasses 46 139-43

[8] Navarro M, del Valle S, Martinez S, Zeppetelli S, Ambrosio L, Planell J A and Ginebra M P 2004 New macroporous calcium phosphate glass ceramic for guided bone regeneration Biomaterials 25 4233-41

[9] Ota Y, Iwashita T, Kasuga T, Abe Y and Seki A 2000 Bioceramics 192 421-4

[10] Shin H I, Cho H M, Ryoo H M, Kim S Y, Chung J H, Oh S H and Kim S Y 2003 Bioceramics 15 419-22

[11] Van Wazer J 1958 Phosphorus and its Compounds vol 1 (New York: Interscience)

[12] Hoppe U 1996 A structural model for phosphate glasses J. Non-Cryst. Solids 195 138-47

[13] Meyer K 1997 Characterization of the structure of binary zinc ultraphosphate glasses by infrared and Raman spectroscopy J. Non-Cryst. Solids 209 227-39

[14] Losso P, Schnabel B, Jager C, Sternberg U, Stachel D and Smith D O 1992 P-31 NMR investigations of binary alkaline-earth phosphate-glasses of ultra phosphate composition J. Non-Cryst. Solids 143 265-73

[15] Hoppe U, Walter G and Stachel D 1992 The short-range order of metaphosphate glasses investigated by $x$-ray-diffraction Phys. Chem. Glasses 33 216-21

[16] Rothammel W, Burzlaff $\mathrm{H}$ and Specht R 1989 Structure of calcium meta-phosphate $\mathrm{Ca}\left(\mathrm{PO}_{3}\right)_{2}$ Acta Crystallogr. C 45 551-3

[17] Alam T M, Liang J J and Cygan R T 2000 Molecular dynamics simulations of the lithium coordination environment in phosphate glasses Phys. Chem. Chem. Phys. 2 4427-32

[18] Speghini A, Sourial E, Peres T, Pinna G, Bettinelli M and Capobianco J A 1999 Structural investigation of $\mathrm{NaPO}_{3}$ glass using molecular dynamics simulation Phys. Chem. Chem. Phys. 1 173-7

[19] Sourial E, Peres T, Capobianco J A, Speghini A and Bettinelli M 1999 A structural investigation of $\mathrm{Mg}\left(\mathrm{PO}_{3}\right)_{(2)}$, $\mathrm{Zn}\left(\mathrm{PO}_{3}\right)_{(2)}$ and $\mathrm{Pb}\left(\mathrm{PO}_{3}\right)_{(2)}$ glasses using molecular dynamics simulation Phys. Chem. Chem. Phys. $12013-8$

[20] Clark E B, Mead R N and Mountjoy G 2006 A molecular dynamics model of the atomic structure of $\mathrm{Tb}$ metaphosphate glass $\left(\mathrm{Tb}_{2} \mathrm{O}_{3}\right)_{(0.25)}\left(\mathrm{P}_{2} \mathrm{O}_{5}\right)_{(0.75)}$ J. Phys. Condens. Matter 18 6815-26

[21] Hoppe U, Walter G, Kranold R and Stachel D 2000 Structural specifics of phosphate glasses probed by diffraction methods: a review J. Non-Cryst. Solids $26329-47$

[22] Sistla R K and Seshasayee M 1999 Reverse Monte Carlo study of the $40 \mathrm{Li}_{(2)} \mathrm{O}-60 \mathrm{P}_{(2)} \mathrm{O}_{(5)}$ glass Solid State Commun. $11335-9$
[23] Hoppe U, Kranold R, Barz A, Stachel D, Neuefeind J and Keen D A 2001 Combined neutron and x-ray scattering study of phosphate glasses J. Non-Cryst. Solids 293 158-68

[24] Hoppe U, Walter G, Stachel D and Hannon A C 1996 Short-range order in $\mathrm{KPO}_{3}$ glass studied by neutron and $\mathrm{x}$-ray diffraction $Z$. Naturf. a $\mathbf{5 1} 179-86$

[25] Bionducci M, Licheri G, Musinu A, Navarra G, Piccaluga G and Pinna G 1996 The structure of a Zn(II) metaphosphate glass. 1 . The cation coordination by a combination of x-ray and neutron diffraction, EXAFS and $\mathrm{x}$-ray anomalous scattering Z. Naturf. a 51 1209-15

[26] Hoppe U, Walter G, Carl G, Neuefeind J and Hannon A C 2005 Structure of zinc phosphate glasses probed by neutron and $\mathrm{x}$-ray diffraction of high resolving power and by reverse Monte Carlo simulations J. Non-Cryst. Solids 351 1020-31

[27] Navarra G, Falqui A, Piccaluga G and Pinna G 2002 The structure of a zinc metaphosphate glass. A reverse Monte Carlo study Phys. Chem. Chem. Phys. 4 4817-22

[28] Hoppe U 2008 Rare-earth site distributions in $\mathrm{R}\left(\mathrm{PO}_{3}\right)_{(3)}$ $(\mathrm{R}=\mathrm{La}, \mathrm{Nd}, \mathrm{Er}, \mathrm{Yb})$ metaphosphate glasses by reverse Monte Carlo simulations J. Phys.: Condens. Matter 208

[29] Mountjoy G, Anderson R, Bowron D T and Newport R J 1998 Reverse Monte Carlo modelling of Eu and $\mathrm{Tb}$ metaphosphate glasses J. Non-Cryst. Solids 234 227-33

[30] Pickup D M, Ahmed I, Guerry P, Knowles J C, Smith M E and Newport R J 2007 The structure of phosphate glass biomaterials from neutron diffraction and P-31 nuclear magnetic resonance data J. Phys.: Condens. Matter 19415116

[31] Hannon A C 2005 Results on disordered materials from the general materials diffractometer, GEM, at ISIS Nucl. Instrum. Methods Phys. Res. A 551 88-107

[32] McGreevy R and Pusztai L 1988 Reverse Monte Carlo simulation: a new technique for the determination of disordered structures Mol. Simul. 1 359-67

[33] Evrard G and Pusztai L 2005 Reverse Monte Carlo modelling of the structure of disordered materials with $\mathrm{RMC}++\mathrm{a}$ new implementation of the algorithm in $\mathrm{C}++J$. Phys. Condens. Matter 17 S1-3

[34] Fletcher D A, McMeeking R F and Parkin D 1996 The United Kingdom chemical database service J. Chem. Inf. Comput. Sci. 36 746-9

[35] Pickup D M, Guerry P, Moss R M, Knowles J C, Smith M E and Newport R J 2007 New sol-gel synthesis of a $(\mathrm{CaO})_{(0.3)}\left(\mathrm{Na}_{2} \mathrm{O}\right)_{(0.2)}\left(\mathrm{P}_{2} \mathrm{O}_{5}\right)_{(0.5)}$ bioresorbable glass and its structural characterisation J. Mater. Chem. 17 4777-84

[36] Hoppe U, Brow R K. Ilieva D, Jovari P and Hannon A C 2005 Structure of rare-earth phosphate glasses by $\mathrm{x}$-ray and neutron diffraction J. Non-Cryst. Solids 351 3179-90

[37] Greenwood N N and Earnshaw A 1997 Chemistry of the Elements (Oxford: Butterworth-Heinemann)

[38] Brown I D 1988 What factors determine cation coordination numbers Acta Crystallogr. B 44 545-53

[39] Hoppe U, Stachel D and Beyer D 1995 The oxygen coordination of metal-ions in phosphate and silicate-glasses studied by a combination of x-ray and neutron-diffraction Phys. Scr. T 57 122-6

[40] Hoppe U, Walter G, Stachel D and Hannon A C 1995 Short-range order details of metaphosphate glasses studied by pulsed-neutron scattering Z. Naturf. a 50 684-92

[41] Hoppe U, Kranold R, Stachel D, Barz A and Hannon A C 1998 $A$ neutron and $\mathrm{x}$-ray diffraction study of the structure of the $\mathrm{LaP}_{3} \mathrm{O}_{9}$ glass J. Non-Cryst. Solids 44 232-4

[42] Mead R N and Mountjoy G 2006 A molecular dynamics study of the atomic structure of $(\mathrm{CaO})_{(x)}\left(\mathrm{SiO}_{2}\right)_{(1-x)}$ glasses J. Phys. Chem. B 110 14273-8

[43] Thomas B W M, Mead R N and Mountjoy G 2006 A molecular dynamics study of the atomic structure of $(\mathrm{CaO})_{(x)}\left(\mathrm{Al}_{2} \mathrm{O}_{3}\right)_{(1-x)}$ glass with $x=0.625$ close to the eutectic J. Phys.: Condens. Matter 18 4697-708

[44] Brese N E and Okeeffe M 1991 Bond-valence parameters for solids Acta Crystallogr. B 47 192-7 